\title{
Mortality by Lesions Caused by Transit on the Tri- Country Border Shared by Brazil, Paraguay and Argentina
}

\author{
Eduardo Wolfgram, Thiago Luis de Andrade Barbosa and Ludmila Mourão Xavier Gomes* \\ Federal University of Latin America Integration, School of Medicine, Brazil
}

\begin{abstract}
Purpose: To analyse the lesions caused transit (LCTs) mortality trend on the tri-country border shared by Brazil (Paraná), Argentina and Paraguay.

Methods: A retrospective time-series study between 1996 and2015 carried out in 17 municipalities of Paraná, located on the border with Paraguay and Argentina in comparison with non-frontier region. There was a calculation of mortality rates and verified the mortality trend through polynomial regression.

Results: The behavior of mortality rates by LCTs throughout the period was increased in all the regions studied, comparing the first to the last year of the time-series analysis. Only the border region showed an increasing, however without statistically significant trend $(p=0.238)$. There was a higher risk of death by LCTs in men in all age groups, especially among younger age groups (20-29 years). The trend of motorcyclists' mortality stood out with the greatest increase among causes of death by LCTs at border region $(p<0.001)$ and non-border region $(p<0.001)$.
\end{abstract}

Conclusion: Deaths by LCTs remains as an important public health problem involving the studied regions, serving as a subsidy for the adoption of new public policies and the continuity of others, especially with the motorcyclists' group.

KEYWORDS: Mortality external causes; Accidents; Traffic; Border areas

\section{INTRODUCTION}

In the globalised world, death by lesions caused by transit (LCTs) constitutes an important public health problem that afflicts both high-income and low-income countries [1]. More than 1.2 million people die on highways annually. LCTs present a challenge for policy agendas and for governments and are the principal cause of deaths among people aged between 15 and 20 years [2]. Nearly $90 \%$ of all LCTs occur in developing countries [3]. In Brazil, there are approximately 45,000 deaths per year. Besides the lives lost, the suffering of families and the aftereffects for survivors, this means elevated costs for health systems [4].

Recently, the flow of people, vehicles and merchandise has increased on Brazil's borders, principally in the Centre South, through trans-border relationships. This phenomenon grew with the creation and strengthening of public policies that sought South American integration, the realisation of which, with the operationalisation of the Common Market of the South (Mercosul), strengthened the region politically and economically [5]. On the borders, different political, financial, safety and social protection systems exist side by side. The increase in the flow of products, services and people as an outcome of integration generates turbulence and challenges for the health systems of neighbouring cities, demanding the creation and application of specific policies directed at guaranteeing the universal right to healthcare.

With regard to the border areas of economic and political importance to Brazil, we may highlight the area of the State of
Quick Response Code:

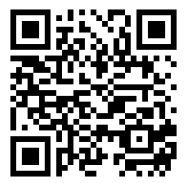

Address for correspondence: Ludmila Mourão Xavier Gomes, Tarquínio Joslin dos Santos Avenue, University Garden, Foz do Iguaçu, Brazil

Received: August 21, $2020 \quad$ Published: October 08, 2020

How to cite this article: Eduardo W, Thiago L de AB, Ludmila MXG. Mortality by Lesions Caused by Transit on the Tri-Country Border Shared by Brazil, Paraguay and Argentina. 2020 - 2(5) OAJBS.ID.000223. DOI: $10.38125 / \mathrm{OAJBS} .000223$ 
Paraná in southern Brazil, 17 of whose municipalities border Paraguay and Argentina. In this area, the dynamic of a floating population exists, and that has an impact on the tourist, social and economic conditions of each region [6].

Many foreigners seek temporary employment in the countryside of the Brazilian border towns. The flow of vehicles and people are particularly intense in the tri-country border area that brings together Brazil (Foz do Iguaçu), Paraguay, (Ciudad del Este) and Argentina (Puerto Iguazú). In large part, this dynamic is a result of various transport services that operate over the international bridge, carrying products and people [7]. However, one does not know in detail the real situation of LCTs in the regions of Brazil's international borders. In this sense, the analysis of deaths by LCTs represents an important element in fostering public policies that reduce vehicle accident rates. This study sought to analyse the LCT mortality trend on the tri-country border shared by Brazil (Paraná), Argentina and Paraguay.

\section{METHODS}

\section{Source Date and Variables}

This is a retrospective time-series study on mortality caused by LCTs in Paraná, in the South of Brazil, between 1996 and 2015 in 17 municipalities located on the border shared with Paraguay and Argentina, as well as that in the other 382 municipalities in the State of Paraná (Figure 1).

Figure 1: Map of the tri-country border shared by Brazil (Paraná). Argentina and Paraguay.

The State of Paraná shares a $447 \mathrm{~km}$ border with these two countries. The municipalities that directly share a border were labelled border region (BR), and the others, without any international borders, were labelled non-border region (NBR). The geographic regions were considered territorial unities as the set of municipalities remained stable during the series. Population data were obtained from estimates and from the Demographic Census of 2010 of the Brazilian Institute of Geography and Statistics (IBGE). Registrations of deaths by LCTs were obtained from the Brazilian SIM (Mortality Information System). The causes of death involving LCTs corresponded to categories V01-V89 of Chapter XX of the 10th International Classification of Diseases per place of occurrence. Data regarding deaths were analyzed according to gender, age group, marital state, rate of schooling, color of skin, locale of occurrence and condition of the victim. As we worked with publicly available data, this work of research does not have to be approved by the Ethics Committee on Research with Human Beings. No informed consent was necessary, given the retrospective nature of this study.

\section{STATISTICAL ANALYSIS}

To calculate crude mortality rates by LCTs, we divided the number of deaths by the population of the period and multiplied the result by 100 thousand inhabitants with reference to each year of the period of study. Death rates by LCTs were calculated for global mortality, pedestrians, cyclists, motorcyclists and occupants of motor vehicles for each region. To obtain comparability, all of these indicators were standardized by age, utilizing the direct method with the standard population of the 2010 IGBE census. We used the direct method to be able to compare two or more populations with differences in their age structures. We then proceeded to the delimitation of a standard population that became a reference for other years of the time-series [8]. The cases with information "not known" were not included. Relative risk and confidence intervals of 95\% were calculated, with the female gender as a reference.

For verifying the death trend in the period analysed, we adopted the polynomial regression method. This model facilitates preparation and interpretation and possesses great statistical power. The four mortality rates standardized for different categories of LCTs were employed as variables, while the ensuing years were utilized as independent variables. This was centralised at the middle point of the series to avoid autocorrelation between terms in the regression equation. Dispersion parcels of independent variables were used for the function that best expressed the relationship between them. Subsequently, the first-order, secondorder, third order and exponential were tested, where $\beta 0$ is the average coefficient for the period, and $\beta 1$ is the average annual rate. The choice of model was based on the following criteria: best function according to the dispersion diagram, normality of errors and homoscedasticity, greater statistical significance and greater determination coefficient. In the cases of statistically similar models, the simplest was selected. A significance level of 5\% was used for polynomial regression. To analyse the mortality trend by LCTs and the construction of the map, the Tabwin 4.14 programme of the Informatics Department of Brazil's Sistema Único de Saúde (SUS) was used, and so was the Bioestat 5.0 statistics software of the Federal University of Pará in Brazil. 


\section{RESULTS}

Table 1 presents the sociodemographic and relative characteristics of deaths by LCTs occurred. Men constitute the most affected group, for both BR and NBR. There was a great difference of percentage values between male and female deaths. The age group most affected was young adults (20-39 years), with over $40 \%$ of deaths in all regions analysed, and the principle place of occurrence being public streets and roads. Occupants of automobiles were the principal victims in NBR and in Paraná $(25.7 \%$ and $25.5 \%$, respectively); however, in $\mathrm{BR}$, pedestrians (28\%) were the most affected.

Table 1: Description of deaths by lesions caused by transit, according to geographic region, State of Paraná, South of Brazil, 1996-2015.

\begin{tabular}{|c|c|c|c|c|c|c|c|c|c|}
\hline \multirow{2}{*}{ Variables } & \multicolumn{3}{|c|}{ BR } & \multicolumn{3}{|c|}{ NBR } & \multicolumn{3}{|c|}{ Paraná } \\
\hline & $\%$ & CI & $95 \%$ & $\%$ & CI & $95 \%$ & $\%$ & CI & $95 \%$ \\
\hline \multicolumn{10}{|c|}{ Sex } \\
\hline Male & 80.8 & 79.1 & 82.4 & 80.6 & 80.2 & 81 & 80.7 & 80.3 & 81 \\
\hline Female & 19.2 & 15.8 & 22.6 & 19.4 & 18.7 & 20.1 & 19.3 & 18.6 & 20 \\
\hline \multicolumn{10}{|c|}{ Age group } \\
\hline $0-9$ years & 3.6 & -0.1 & 7.3 & 3.9 & 3.1 & 4.7 & 3.8 & 3.1 & 4.6 \\
\hline $10-19$ years & 14.4 & 11 & 17.9 & 11.8 & 11 & 12.6 & 11.8 & 11.1 & 12.6 \\
\hline 20-29 years & 24.5 & 21.2 & 27.8 & 24.1 & 23.4 & 24.8 & 24.1 & 23.4 & 24.8 \\
\hline 30-39 years & 18 & 14.6 & 21.4 & 19 & 18.2 & 19.7 & 18.9 & 18.2 & 19.6 \\
\hline 40-49 years & 14.4 & 10.9 & 17.9 & 15.7 & 14.9 & 16.4 & 15.6 & 14.9 & 16.3 \\
\hline 50-59 years & 11.4 & 7.8 & 14.9 & 11.3 & 10.5 & 12.1 & 11.4 & 10.6 & 12.1 \\
\hline 60 years or older & 13.7 & 10.2 & 17.2 & 14.3 & 13.5 & 15 & 14.4 & 13.6 & 15.1 \\
\hline \multicolumn{10}{|c|}{ Marital Status } \\
\hline Single & 56.4 & 53.9 & 59 & 51.5 & 50.9 & 52.1 & 51.8 & 51.2 & 52.4 \\
\hline Married or Stable Union & 35 & 31.9 & 38.2 & 38.8 & 38.2 & 39.5 & 38.4 & 37.8 & 39.1 \\
\hline Widower & 4.6 & 0.7 & 8.4 & 4.9 & 4.1 & 5.8 & 5 & 4.2 & 5.8 \\
\hline Divorced & 3.9 & 0.1 & 7.8 & 4.7 & 3.9 & 5.5 & 4.8 & 4 & 5.6 \\
\hline \multicolumn{10}{|c|}{ Education } \\
\hline$\leq 03$ years & 27.9 & 24.2 & 31.5 & 294 & 28.6 & 30.2 & 28.7 & 28 & 29.5 \\
\hline 04-07 years & 32 & 28.4 & 35.5 & 33.8 & 33 & 34.6 & 33.6 & 32.9 & 34.3 \\
\hline 08-11 years & 29.7 & 26.1 & 33.3 & 26.1 & 25.2 & 26.9 & 27 & 26.2 & 27.8 \\
\hline$\geq 12$ years & 10.5 & 6.5 & 14.5 & 10.7 & 9.8 & 11.6 & 10.7 & 9.8 & 11.5 \\
\hline \multicolumn{10}{|c|}{ Skin colour } \\
\hline White & 82.2 & 80.5 & 83.9 & 87 & 86.6 & 87.3 & 86.6 & 86.3 & 86.9 \\
\hline Brown & 15.2 & 11.4 & 18.9 & 10.2 & 9.4 & 11.1 & 10.6 & 9.8 & 11.4 \\
\hline Other & 2.6 & -1.4 & 6.6 & 2.8 & 2 & 3.7 & 2.8 & 2 & 3.6 \\
\hline \multicolumn{10}{|c|}{ Place of Occurence } \\
\hline Hospital & 41.4 & 38.4 & 44.3 & 40.4 & 39.7 & 41 & 40.3 & 39.7 & 40.9 \\
\hline Public streets and roads & 50.3 & 47.6 & 53 & 53 & 52.4 & 53.6 & 52.9 & 52.3 & 53.4 \\
\hline Other locations & 8.3 & 4.7 & 12 & 6.6 & 5.8 & 7.4 & 6.8 & 6 & 7.6 \\
\hline \multicolumn{10}{|c|}{ Victim category } \\
\hline Pedestrian & 28 & 24.9 & 31.2 & 24.5 & 23.8 & 25.2 & 24.8 & 24.1 & 25.5 \\
\hline Cyclist & 3.4 & -0.3 & 7.1 & 4.8 & 4 & 5.6 & 4.8 & 4 & 5.6 \\
\hline Motorcyclist & 13.8 & 10.3 & 17.3 & 16.5 & 15.7 & 17.2 & 16.8 & 16.1 & 17.5 \\
\hline Automobile occupant & 11.3 & 7.7 & 14.8 & 25.7 & 25 & 26.4 & 25.5 & 24.8 & 26.2 \\
\hline Pick up truck occupant & 0.2 & -3.6 & 3.9 & 0.8 & 0 & 1.6 & 0 & 0 & 0 \\
\hline Heavy vehicle occupant & 0.8 & -2.9 & 4.6 & 2.3 & 1.5 & 3.1 & 2.2 & 1.5 & 3 \\
\hline Bus occupant & 0.1 & -3.6 & 3.9 & 0.5 & -0.4 & 1.3 & 0.5 & -0.3 & 1.3 \\
\hline Others & 42.3 & 39.5 & 45.2 & 24.9 & 24.2 & 25.7 & 25.4 & 24.7 & 26.1 \\
\hline
\end{tabular}

BR: Border region, municipalities that directly share a border; NBR: Non-border region, municipalities without any international border; Cl 95\%: Confidence Interval 95\% 
With regard to the total mortality rate and mortality rate by gender (Table 2), we found the highest average in NBR and Paraná (38.8 and 38.5, respectively) and among men, with values near to 50 deaths per 100,000 inhabitants (49.6 and 49.7, respectively). Women presented the greatest percentage reduction of deaths by LCTs in the two regions presented $455.5 \%$ in NBR and $45.2 \%$ in
Paraná) upon comparing the first and last year of the time series. We found a greater risk for men when compared with women in all age groups. For men, higher mortality rates were observed in younger age groups (20-29 years); for women, the rates are greater in the age group 60 years or older. The RR between genders was higher in the 20-39-year group in BR and other regions (Table 3).

Table 2: Average mortality rate of traffic accidents per 100.000 inhabitants. by age group and sex. according to geographic region. State of Paraná. South of Brazil. 1996-2015.

\begin{tabular}{|c|c|c|c|c|}
\hline \multirow{2}{*}{$\begin{array}{c}\text { Geographic region/ } \\
\text { Age group }\end{array}$} & \multicolumn{4}{|c|}{ Mortality rate } \\
\hline & Total & $\mathbf{M}$ & $\mathbf{F}$ & $\mathbf{R} \mathbf{R}$ \\
\hline \multicolumn{5}{|c|}{ BR } \\
\hline $0-9$ years & 0.8 & 1.2 & 0.4 & 2.9 \\
\hline 10-19years & 3.9 & 5.9 & 2 & 2.9 \\
\hline 20-29years & 6.5 & 11.2 & 2 & 5.6 \\
\hline 30-39years & 5 & 8.3 & 1.7 & 5 \\
\hline 40-49years & 4.5 & 7.5 & 1.5 & 4.9 \\
\hline 50-59years & 3.8 & 6.4 & 1.3 & 4.9 \\
\hline 60 years or older & 4.8 & 7.4 & 2.3 & 3.2 \\
\hline \multicolumn{5}{|c|}{ NBR } \\
\hline $0-9$ years & 0.9 & 1.1 & 0.8 & 1.5 \\
\hline 10-19years & 3.3 & 5.1 & 1.6 & 3.2 \\
\hline 20-29years & 6.9 & 11.9 & 2.1 & 5.7 \\
\hline 30-39years & 5.6 & 9.5 & 1.7 & 5.7 \\
\hline 40-49years & 5 & 8.4 & 1.7 & 5 \\
\hline 50-59years & 3.8 & 6.3 & 1.3 & 4.7 \\
\hline 60 years or older & 4.9 & 7.3 & 2.6 & 2.8 \\
\hline \multicolumn{5}{|c|}{ Paraná } \\
\hline $0-9$ years & 1 & 1.1 & 0.7 & 1.5 \\
\hline 10-19years & 3.3 & 5.2 & 1.6 & 3.2 \\
\hline 20-29years & 6.9 & 11.8 & 2.1 & 5.7 \\
\hline 30-39years & 5.5 & 9.5 & 1.7 & 5.6 \\
\hline 40-49years & 4.9 & 8.4 & 1.7 & 5 \\
\hline 50-59years & 3.7 & 6.3 & 1.3 & 4.7 \\
\hline 60 years or older & 4.7 & 7.3 & 2.6 & 2.8 \\
\hline
\end{tabular}

RR: Relative Risk Male/Female; BR: Border region, municipalities that directly share a border; NBR: Non-border region, municipalities without any international border. 
Table 3: Mortality rates due to lesions caused by transit per 100.000 inhabitants. according to sex and geographic region. State of Paraná. South of Brazil. 1996-2015.

\begin{tabular}{|c|c|c|c|c|c|c|c|c|c|}
\hline \multirow{2}{*}{ Year } & \multicolumn{3}{|c|}{ Paraná } & \multicolumn{3}{|c|}{ BR } & \multicolumn{3}{|c|}{ NBR } \\
\hline & $\mathbf{M}$ & $\mathbf{F}$ & Total & M & $\mathbf{F}$ & Total & M & $\mathbf{F}$ & Total \\
\hline 1996 & 60.4 & 16.6 & 37.8 & 54.6 & 16.8 & 35.3 & 60.7 & 16.6 & 38.6 \\
\hline 1997 & 57.6 & 15.1 & 35.7 & 62.4 & 16.6 & 39.5 & 57.5 & 15 & 36.1 \\
\hline 1998 & 51 & 12.2 & 31.1 & 48.3 & 11.2 & 29.8 & 51.2 & 12.3 & 31.6 \\
\hline 1999 & 49.5 & 11.9 & 30.2 & 51.4 & 7.7 & 29.7 & 49.5 & 12.1 & 30.6 \\
\hline 2000 & 44.6 & 10.2 & 26.9 & 42.6 & 11.2 & 26.7 & 44.7 & 10.2 & 27.3 \\
\hline 2001 & 44.9 & 9.6 & 26.8 & 41.5 & 8 & 24.8 & 45.1 & 9.7 & 27.3 \\
\hline 2002 & 46.5 & 9.9 & 27.7 & 37.4 & 10.8 & 23.7 & 47 & 9.9 & 28.3 \\
\hline 2003 & 47.8 & 11 & 28.8 & 43.5 & 12 & 27.7 & 48 & 10.9 & 29.3 \\
\hline 2004 & 52.9 & 12 & 31.9 & 40.3 & 8 & 24.1 & 53.6 & 12.2 & 32.7 \\
\hline 2005 & 50 & 11.4 & 30.1 & 48 & 11.9 & 29.8 & 50.1 & 11.4 & 30.6 \\
\hline 2006 & 48.8 & 10.8 & 29.2 & 54.1 & 10 & 28.3 & 48.5 & 10.9 & 29.6 \\
\hline 2007 & 51.4 & 11.5 & 30.9 & 48.1 & 8.8 & 28.4 & 51.5 & 11.7 & 31.5 \\
\hline 2008 & 50.9 & 11.5 & 30.6 & 54.9 & 14 & 34.2 & 50.7 & 11.4 & 30.9 \\
\hline 2009 & 48.2 & 11.6 & 29.4 & 44.2 & 12.8 & 28.2 & 48.4 & 11.6 & 29.9 \\
\hline 2010 & 53.2 & 12.9 & 31.8 & 56.7 & 11 & 33.3 & 53 & 13 & 32.7 \\
\hline 2011 & 51 & 11.4 & 30.6 & 51.3 & 15.4 & 33.1 & 51 & 11.2 & 31 \\
\hline 2012 & 53.9 & 12.7 & 32.7 & 55.6 & 10.7 & 32.5 & 53.8 & 12.8 & 33.2 \\
\hline 2013 & 46.4 & 10.8 & 28.1 & 46.7 & 8.5 & 27.2 & 46.4 & 11 & 28.6 \\
\hline 2014 & 44 & 11.1 & 27.1 & 39.3 & 10 & 24.4 & 44.2 & 11.1 & 27.6 \\
\hline 2015 & 38.3 & 9.1 & 23.3 & 36.7 & 9.4 & 23 & 38.4 & 9.1 & 23.6 \\
\hline $\begin{array}{c}\text { Average } \\
1996-2015\end{array}$ & 49.6 & 11.7 & 30 & 47.9 & 11.2 & 29.2 & 49.7 & 11.7 & 30.6 \\
\hline $\begin{array}{c}\Delta \% \\
1996 / 2015\end{array}$ & -36.5 & -45.2 & -38.4 & -32.7 & -44 & -34.9 & -36.7 & -45.5 & -38.8 \\
\hline
\end{tabular}

F: Female; M: Male; BR: Border region; municipalities that directly share a border; NBR: Non-border region; municipalities without any international border.

The behavior of mortality rates by LCTs throughout the time series (Table 4); (Figure 2) was one of reduction in all regions studied when the first year was compared with the last year of the series. Among the regions studied, only BR revealed a falling trend, but even that was without statistical significance ( $p=0.238$ ) (Table 4). There was accelerated growth in the number of deaths by LCTs between 2002 and 2012 and a reduction in the following years in that region. Specific rates by type of victim showed regional disparities. For pedestrians, the highest rates were found in BR up to 2006, after which NBR and Paraná were superior for all years, except for 2014 and 2015. Between 1996 and 2015, all regions presented decreasing and significant trends of the values: $59.8 \%$ in BR $(p=0.001), 65.8 \%$ in NBR $(p=0.001)$ and $65.4 \%$ in Paraná $(p=0.001)$. Cyclist mortality was low most of the time in the regions studied, with a stationary trend in spite of observing a reduction of $63.5 \%$ in BR, an increase of $32.3 \%$ in NBR, and 34.9\% in Paraná throughout the time-series [9].

Motorcyclist mortality presented lower rates in BR most of the time in spite of having greater values at some points of the series. In 2011, the difference between regions reached its maximum in which BR exceeded the other regions, remaining high. Moreover, the type of victim presented a significant increase in the time series. There was a growing trend in BR, with an increase of 22.5 times the risk $(p<0.001), 4.0$ times in NBR $(p<0.001)$ and 4.2 times in Paraná $(p<0.001)$. The mortality rates of vehicle occupants were in all years higher in NBR and Paraná, when compared to BR. With some oscillations during the series, the rates presented an increase in all regions, particularly for NBR $(10.8 \%)$ and Paraná $(10.2 \%)$, which showed increasing and significant trends $(p=0.001 ; p=$ 0.001 , respectively).

\section{DISCUSSION}

The findings of the study point to a situation of death by LCTs in two regions of Brazil located in the State of Paraná upon comparing them with areas with an international border and those without an international border. Distinct trends are observable in the analysis of 20 years, and that may aid in the formulation of public policies with interventions that are more effective. In this period , the results point to a worrisome situation, with high mortality because of the rate of LCTs in men and young adults in BR. In this study, young people were the most affected, which is similar to the Brazilian scenario, with $43 \%$ of deaths [10], as well as scenarios in other countries such as Rwanda and Libya [11-13]. In Bahia, in the northeast of Brazil [14], mortality due to LCTs between 20 and 39 years of age correspond to more than $40 \%$ of all deaths. Young men are the highest consumers of emergency trauma treatments [15]. 
The reduction of the economically active population by LCTs has an impact on individuals, families, communities and the country and emphasises the urgent need for public policies with special attention to the management of speed, application of transit laws, vehicle safety regulations and emergency treatment for victims of LCTs $[16,17]$. In spite of the hypothesis of researchers that mortality rates by LCTs are increasing with an upward trend, this is not what happened in this historical series. Even with the reduction of deaths by this cause, the global trend in this region was stationary, while there was an accelerated increase of deaths in the 2002-2012 period. This increase may be related to the exchange fluctuations that occurred in Brazil in the economic scenario in this period that may have favored the flow and transportation of people, commerce and merchandise. This occurred given the economic activities based on the cultivation of grains, movement of the production through "dry ports" of other regions of Brazil, and of Paraguay and Argentina, and regional food industries.

Table 4: Trends of mortality due to lesions caused by transit (overall and by victim category). According to geographic regions. State of Paraná. South of Brazil. 1996-2015.

\begin{tabular}{|c|c|c|c|c|c|}
\hline Mortality rate & Model* & $\mathbf{R} 2 * *$ & $\beta$ & $\mathbf{p}^{* * *}$ & Trend \\
\hline \multicolumn{6}{|c|}{ Overall } \\
\hline $\mathrm{LF}$ & Linear & 0.025 & -0.275 & 0.238 & Stationary \\
\hline RNF & Linear & 0.166 & -0.425 & 0.042 & Decreasing \\
\hline Paraná & Linear & 0.169 & -0.461 & 0.041 & Decreasing \\
\hline \multicolumn{6}{|c|}{ Pedestrian } \\
\hline $\mathrm{LF}$ & Exponential & 0.799 & -0.9 & $<0.001$ & Decreasing \\
\hline RNF & Exponential & 0.814 & -0.908 & $<0.001$ & Decreasing \\
\hline Paraná & Exponential & 0.848 & -0.925 & $<0.001$ & Decreasing \\
\hline \multicolumn{6}{|c|}{ Cyclist } \\
\hline LF & Cubic & 0.014 & -0.119 & 0.616 & Stationary \\
\hline RNF & Quadratic & $<0.001$ & -0.019 & 0.935 & Stationary \\
\hline Paraná & Linear & $<0.001$ & -0.001 & 0.966 & Stationary \\
\hline \multicolumn{6}{|c|}{ Motorcyclist } \\
\hline $\mathrm{LF}$ & Cubic & 0.79 & 0.895 & $<0.001$ & Increasing \\
\hline RNF & Exponential & 0.849 & 0.926 & $<0.001$ & Increasing \\
\hline Paraná & Exponential & 0.852 & 0.927 & $<0.001$ & Increasing \\
\hline \multicolumn{6}{|c|}{ Vehicle occupant } \\
\hline $\mathrm{LF}$ & Linear & 0.082 & 0.318 & 0.172 & Stationary \\
\hline RNF & Linear & 0.42 & 0.672 & 0.001 & Increasing \\
\hline Paraná & Linear & 0.452 & 0.693 & 0.001 & Increasing \\
\hline
\end{tabular}

*Model: Y Mortality rate due to lesions caused by transit per 100.000 inhabitants (global and victim category); $X=y e a r$ -2005.5; ${ }^{* *}$ R2: Determination coefficient; ${ }^{* * *} \mathrm{p}$-valour of F Test; BR: Border region=municipalities that directly share a border; NBR: Non-border region=municipalities without any international border.

Another factor is tourism in that a previous study showed numerous tourists in the western region of Paraná on the BR277 Highway unfamiliar with the rules or conditions of the road, which may have provoked accidents involving other vehicles and residents of the region [10]. However, in the Brazilian registration system, no information is available for analysis as to whether the death is that of a compatriot tourist or someone from another nationality. This is a possible explanation for the deaths occurring in BR as they are regions that lack structural development. The lack of investment impedes the development of better roads and is associated with roads in bad traffic conditions. In the 20 yearperiod that was studied, there were infrastructure improvement in roads in BR, although these were not sufficient for mortality by LCTs to decrease.

LF presents increased flow because of not only tourism, commerce, or transportation of merchandise but also a floating population of foreigners and Brazilians resident abroad, known as "Braziguayos," who seek treatment within the Brazilian public health system. During the months of planting and harvest, the search for temporary employment is also common as are rural settlements of residents of Paraguay and Argentina. The decrease in rates of LCTs in BR and in the State of Paraná in this study is similar to that in other Brazilian states such as Santa Catarina, São Paulo, the Federal District and Rio de Janeiro [10].

Pedestrians were victims of LCTs, with oscillations during the period studied. However, it is notable that all the regions studied showed a falling trend, a reality that was different from that of a study conducted in Brazil between 1998 and 2010 [18] that showed an increase in pedestrian deaths. Spatial analysis of the LCTs in the State of Paraná, Brazil, showed that pedestrian deaths in urban environments could be attributed to parts of the BR-277 Highway (one of the principal highways of the State) that presented a greater passage through urban areas, limited illumination, two-way traffic, a lower frequency of auxiliary lanes and the absence of traffic signals [19]. Environments with a higher density of pedestrian traffic and that of vehicular traffic, high speeds, imprudence of motorists and complex transit patterns culminate in traffic accidents involving pedestrians $[18,20]$. In areas with high volumes of pedestrian traffic 
and in those where there are high-velocity vehicles, the provision of viaducts, bridges and tunnels that permit uninterrupted flow is recommended, separating pedestrians from vehicular traffic [16]. In spite of the fact that pedestrians have frequently been victims of LCTs, the falling trend may reveal a greater recent concern for pedestrians, including that in road planning [14]. For cyclists, the decrease of rates may indicate an increase in citizen awareness in terms of respect for transit sharing and the construction of cycle paths.

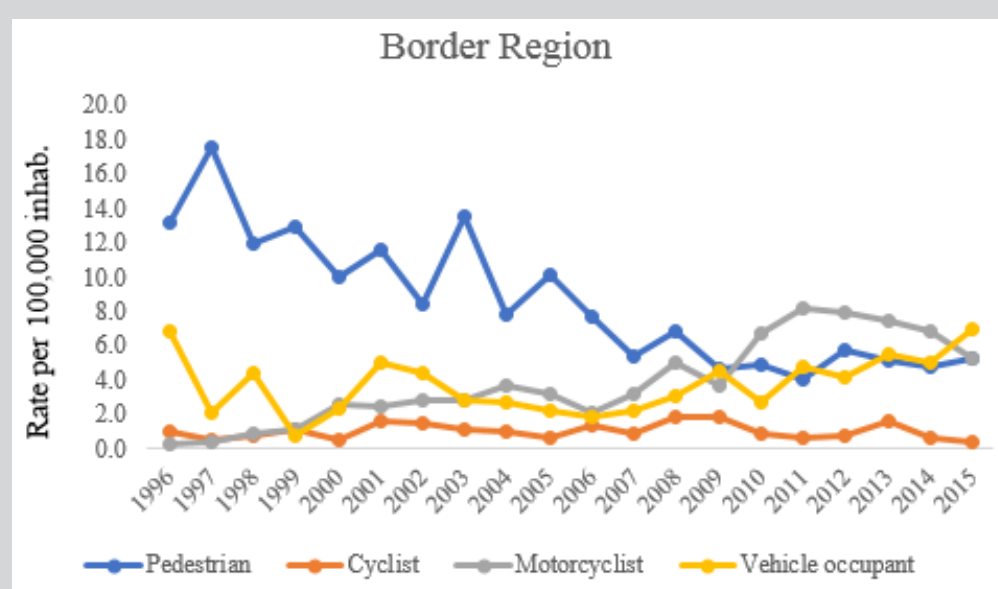

Non-border Region

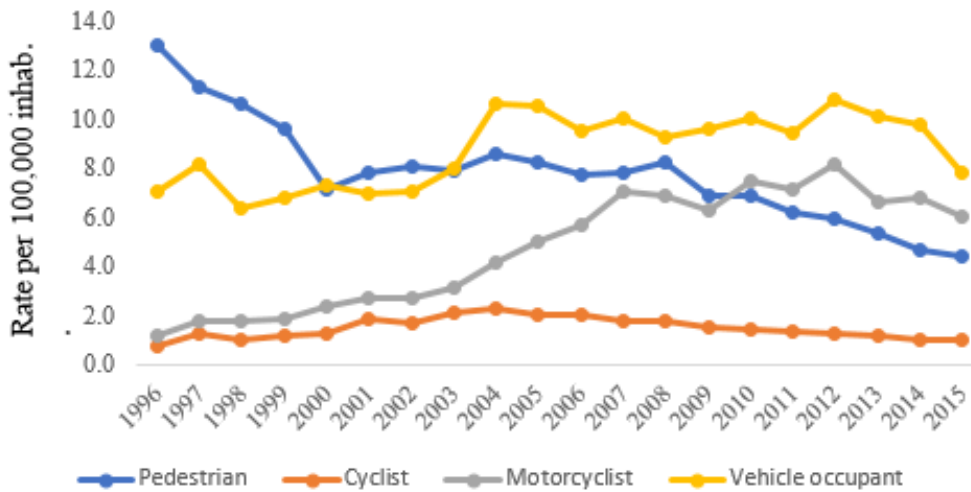

Paraná

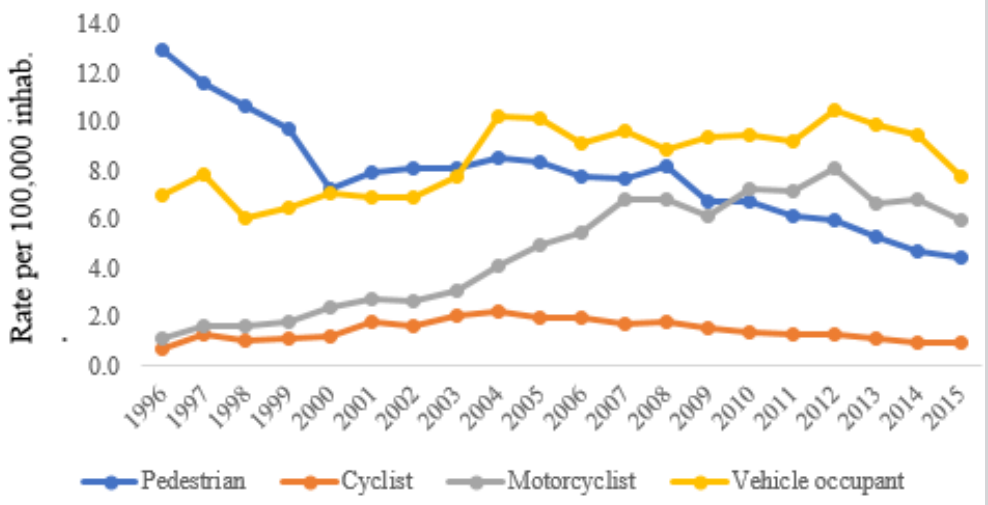

Figure 2: Global evolution of mortality rates due to lesions caused by transit per 100.000 inhabitants according to cause of death and geographic regions, State of Paraná, South of Brazil, 1996-2015.

The significant growth in the mortality of motorcyclists is something that stands out in this research. In NBR, motorcyclists were the group that presented the highest rates when compared with the other regions. The high mortality rates, the number of accidents and the motorcycle fleet in the Americas reflect a gap between rapid urban growth and the slow development of public transportation systems [21,22]. The increase in the fleet is due, among other reasons, to public incentives and the use of motorcycles as employment equipment, which is very common at the borders [23] as well as in urban centres. One explanation would be the low acquisition and maintenance cost of this type of vehicle, the regularisation of moto-taxi service and the advent of an economic model based on outsourcing [14]. Of note is the low cost of motorcycles and the increase in their use as a work vehicle because of the facility of access and transit at the border, with less time spent when compared to a situation involving an automobile. Also discussed is precariousness and differences in the application of the law in smaller municipalities and in other bordering 
countries studied that may contribute to this state of affairs. In $\mathrm{BR}$, commercial issues and employment supply result in Brazilians crossing the border daily on the way to work in the country, with the motorcycle being the principal vehicle used because of its speed and economy. This fact may contribute to elucidate the increase of rates and the important concern regarding the adoption of public policies that involve this public.

In the face of high mortality due to LCTs among motorcyclists, general criteria of good highway practice should be established, such as speed controls in urban areas, restriction on inebriatedness while driving and the use of properly worn helmets. Besides these, of special interest is the construction of specific routes for cyclist and motorcyclist traffic separate from automobile traffic, with these roads being a safer environment than the main road. Antilock braking systems that impede the locking of wheels during braking and help the motorcyclist to maintain stability and the control of direction while braking suddenly could be used as a public policy initiative. Another important mechanism is day headlights that increase the visibility of motorcycles for other road users, diminishing errors related to visibility [16].

Vehicle occupants present increasing rates in NBR and in Paraná, with a stationary trend in BR. Locales near roads and with high traffic volumes in the northeast of the country also show a growing trend and should be a cause for concern. In NBR, the predominance of victims as occupants of vehicles might be related to accidents on roads of national and regional importance that pass through many cities [14]. It is of note that this region concentrates most of the population of the state. The adoption of measures aimed at minimizing LCTs with occupants of vehicles is vital in both nonborder and border areas.

\section{LIMITATIONS}

This study has some limitations that are inherent to studies that use secondary data. The SIM, although having shown improvements over time, may present notifications that are insufficient or deficient with regard to the basic causes of deaths because of external causes. Some data of great interest, such as nationality of the victim, could not be obtained through the SIM. In addition, another limitation is related to the fact that the data reflect the reality of a border region of Brazil only from 1996 to 2015, given that this was a period for which data were available in the data bank of the country. In spite of this, we reemphasise that this study is of high relevance for countries and for health management at the local and regional levels, given that it calls attention to the growing trend of deaths because of LCTs, which merits more detailed research for a better understanding of this reality.

\section{HIGHLIGHTS}

a) This is first study to verify the profile of mortality by lesions caused by transit in a reality of tri-national frontier, allowing comparative analysis with the non-border region of an brazilian state.

b) Mortality rates by LCTs throughout the period was increased in all the regions studied, comparing the first to the last year of the time-series analysis. Only the border region did not show significant increasing.

c) Higher risk of death by LCTs in men in all age groups was identified as significant, especially among younger age groups (2029 years) d) Motorcyclists' mortality stood out with the greatest increase among causes of death by LCTs was identified as significant at border region and non-border region.

\section{CONCLUSION}

Finally, this study makes possible the recognition of an important public health problem in BR, emphasising the triple border area, and serves as a support for professionals who work with transit; for local, regional and state management; and for neighbouring countries in the adoption of public policies principally aimed at the prevention of LCTs among motorcyclists. These policies should be accompanied by the implementation of laws and by rigour according to current legislation, with special attention paid to the management of speed, vehicle safety standards and emergency assistance to victims, so as to reduce mortality because of LCTs.

\section{ACKNOWLEDGMENT}

To Conselho Nacional de Desenvolvimento Científico e Tecnológico in Brazil (CNPq) for funding the research project and scientific initiation scholarship.

\section{REFERENCES}

1. Zangi Abadi A, Shiran GHR, Gshtyl Kh (2012) Causes of accidents on motorways (Case Study: Urban Highways Esfahan). Journal of Science and Promotion 9(17): 17-57.

2. World Health Organization (2015) Global status report on road safety.

3. Gicquel L, Ordonneau P, Blot E, Toillon C, Ingrand P, et al. (2017) Description of various factors contributing to traffic accidents in youth and measures proposed to alleviate recurrence. Front Psychiatry 8: 94.

4. IPEA. Estimativa dos custos dos acidentes de trânsito no Brasil com base na atualização simplificada das pesquisas anteriores do Ipea: relatório de pesquisa viária.

5. Gadelha CAG, Costa L (2007) Integration of borders: health in the national development policy context. Cad Saúde Pública 23(2): 214-226.

6. Souza ML, Ferreira LAP, Rezende VM, Branco ML (2008) A saúde e inclusão social nas fronteiras.

7. Rabossi F (2015) Tempo e movimento em um mercado de fronteira: Ciudad del Este, Paraguai. Sociol Antropol 5(2): 405-434

8. Gordis L (2004) Measuring the occurrence of disease: II. Mortality. In: Gordis L, [ed.], Epidemiology $3^{\text {rd }}$ [Edn], Elsevier Saunders, Philadelphia.

9. Latorre MRDO, Cardoso MRA (2001) Time series analysis in epidemiology: an introduction to methodological aspects. Rev Bras Epidemiol 4(3): 145-152.

10. Brasil, Ministério da Saúde. Saúde Brasil 2014: uma análise da situação de saúde e das causas externas. Brasília (DF): Ministério da Saúde (BR).

11. Organização Mundial da Saúde (2015) Relatório global sobre o estado da segurança viária. Genebra: Organização Mundial da Saúde.

12. Bodalal Z, Bendardaf R, Ambarek M (2012) A study of a decade of road traffic accidents in Benghazi-Libya: 2001 to 2010. PLoS One 7(7): e40454.

13. Patel A, Krebs E, Andrade L, Rulisa S, Vissoci JRN, et al. (2016) The epidemiology of road traffic injury hotspots in Kigali, Rwanda from police data. BMC Public Health 16(1): 697.

14. Rios PAA, Mota ELA (2013) Traffic deaths: recent evolution and regional differences in Bahia State, Brazil. Cad Saúde Pública 29(1): 131-144.

15. Cordellieri P, Baralla F, Ferlazzo F, Sgalla R, Piccardi L, et al. (2016) Gender effects in young road users on road safety attitudes, behaviors and risk perception. Front Psychol 7: 1412.

16. World Health Organization Save lives: a road safety technical package. Geneva: World Health Organization. 
17. Oviedo-Trespalacios O, Haque MM, King M, Washington S (2017) Effects of road infrastructure and traffic complexity in speed adaptation behaviour of distracted drivers. Accid Anal Prev 101: 67-77.

18. Bacchieri G, Barros AJD (2011) Acidentes de trânsito no Brasil de 1998 a 2010: Muitas mudanças e poucos resultados. Rev Saúde Pública 45(5): 949-963.

19. De Andrade L, Vissoci JRN, Rodrigues CG, Finato K, Carvalho E, et al. (2014) Brazilian road traffic fatalities: a spatial and environmental analysis. PLoS One 9(1): e87244.

20. Peltola H, Rajamäki R, Luoma J (2013) A tool for safety evaluations of road improvements. Accid Anal Prev 60: 277-288.
21. Chichom-Mefire A, Atashili J, Tsiagadigui JG, Awah CF, Ngowe-Ngowe M (2015) A prospective pilot cohort analysis of crash characteristics and pattern of injuries in riders and pillion passengers involved in motorcycle crashes in an urban area in Cameroon: lessons for prevention. BMC Public Health 15: 915.

22. Rodrigues EMS, Villaveces A, Sanhueza A, Escamilla-Cejudo JA (2014) Trends in fatal motorcycle injuries in the Americas, 1998-2010. Int J Inj Contr Saf Promot 21(2): 170-180.

23. Diniz EPH, Pinheiro LC, Proietti FA (2015) When and where motorcyclists have accidents and die in Belo Horizonte, Minas Gerais State, Brazil. Cad Saude Publica 31(12): 2621-2634. 